\title{
Correction to: Entertainment Pricing Decisions
}

\section{Correction to: \\ Chapter 14 in: T. Hennig-Thurau and M. B. Houston, Entertainment Science, https://doi.org/10.1007/978-3-319-89292-4_14}

The authors have informed that the Chapter 14 (Entertainment Pricing Decisions) in the original version of the book contained references on Page no. 745 and 783 which were mistakenly attributed to Harold Vogel (2015).

The correct attribution should have been

Page 745

- "Managing price is an art, not a science..."-Ulin (2014, p. 252),

- "We find Jeffrey Ulin's quote to be an intriguing start to a chapter in a book entitled Entertainment Science-Ulin's argument is based on the huge number of highly complex..." citing Ulin, J. C. (2014). The business of media distribution (2nd ed.). New York: Focal Press".

Page 783

- Ulin, J. C. (2014). The business of media distribution (2nd ed.). New York: Focal Press.

The correction has been updated in the current version accordingly.

The updated version of this chapter can be found at https://doi.org/10.1007/978-3-319-89292-4_14 